\title{
ПРОБЛЕМЫ И ПЕРСПЕКТИВЫ СТАНОВЛЕНИЯ В РЕСПУБЛИКЕ БЕЛАРУСЬ ЛОГИСТИЧЕСКОГО КЛАСТЕРА
}

\author{
Ю.В. МЕЛЕШКО \\ Инспектор \\ Минская региональная таможня
}

\begin{abstract}
Аннотация
Статья посвящена вопросам развития белорусского логистического кластера. Дан анализ понятийному аппарату, выделены основные черты, характерные для кластеров. Изучено применение кластерного подходапри разработке стратегии развития экономики Республики Беларусь, уделено внимание организационным формам кластеризачии белоруской экономики. В статье перечислены и рассмотрены дополнительные конкурентные преимущества, которые наравне с использованием основных факторных условий позволят нашей стране интегрироваться в евроазиатское логистическое пространство.
\end{abstract}

Abstract

This article deals with the development of Belarusian logistic cluster. The analysis of the conceptual apparatus is given, and the main features which characterise clusters are marked out in it. The use of cluster approach in the elaboration of the strategy of economic development of the Republic of Belarus is studied, and attention is paid to the organizational forms of clusterization of Belarusian economy. Additional competitive advantages, which will allow our country (as well as the use of the basic factor terms) to integrate into the Euro-Asian logistic space, are enumerated and discussed in this article.

\section{ВВЕДЕНИЕ}

Активно развивающиеся мировые хозяйственные связи являются причиной постоянно растущего мирового товарооборота, что в свою очередь требует непрерывного совершенствования логистических систем доставок. Немалое значение в увеличении межконтинентальных перевозок имеет появление новых союзов, общих рынков, сообществ и содружеств, например Североамериканское соглашение о свободной торговле, Ассоциация стран Юго-Восточной Азии, Европейский союз, Таможенный союз Республики Беларусь, Республики Казахстан и Российской Федерации, Евразийское экономическое пространство. Наглядным примером может служить динамика грузооборота Республики Беларусь: после вступления в силу в 2008 году Договора о создании единой таможенной территории и формировании Таможенного союза грузооборот по всем видам транспорта (кроме трубопроводного) в Беларуси вырос с 62,9 млрд. тонно-километров в 2008 году до 68,1 в 2012 году (для сравнения: в 2005 году грузооборот составлял 53,1 млрд. тонно-километров). [1] 
В разных странах происходит переход от изолированного физического перемещения материальных потоков к координированному взаимодействию поставщиков, перевозчиков, экспедиторов и потребителей, то есть к использованию логистического подхода в процессе организации доставки товара, предусматривающего целостность, системность, оптимизацию суммарных логистических издержек. Таким образом, особенно актуальным для любой страны, не имеющей сильных позиций на мировом рынке, но обладающей благоприятным геоэкономическим положением и при этом желающей влиться в мировую торговую сеть, становиться внедрение логистических подходов в собственное производство как способ сокращения издержек и повышение конкурентоспособности, а также развитие логистического рынка как для собственного потребления, так и для экспорта логистических услуг.

Процесс глобализации мировой экономики вызвал ряд новых тенденций на рынке транспортных услуг, в частности: изменение организации торговли (концентрация товара в крупных распределительных центрах), формирование экономических и политических союзов с целью расширение сферы влияния и коммерческой деятельности, создание совместных предприятий, транснациональных корпораций. Однако наиболее перспективным для экономического развития Республики Беларусь в связи с изменением конфигурации грузопотоков (изменение транспортных путей, изменение объемов перевозки на различных видах транспорта) является тенденция регионализация рынка логистических услуг - создание логистических кластеров.

Понятие «кластер» относительно новое, его ввел М. Портер в 90-х годах при изучении вопроса международных конкурентных преимуществ компании. Хотя предпосылки возникновения теории кластеров появились еще раньше: А. Маршалла в книге «Principles of Economics» рассматривал причины концентрации малых и средних предприятий в рамках промышленных районов. Кластерная тематика получила дальнейшее развитие в работах многих экономистов. Ближайший последователь М.Портера М. Энрайтв статье «Why Clusters are the Way to Win the Game?», опубликованной в 5 номере WorldLink 1995 года, выдвинул концепцию региональных кластеров как географически очерченной агломерации взаимосвязанных фирм. Скандинавские ученые Б. Далум, К. Педерсен и Г. Вилумсенв работе «Technological Life of Cycles: Regional Clusters Facing Disruption» выделили пять типологических признаков кластеров.

Также есть иное направление исследований кластеров, которое носит методический характер. Так в 1999 году были опубликованы результаты исследований «Industrial and Regional Clustersand Comparative Applications, Regional Research Institute» экономистов Э. Бергман и Э. Фезер, где были обобщены существующие подходы, рассмотрены шесть методик выделения кластеров на основе экспертных мнений, специальных индикаторов (коэффициент локализации и др.), таблиц межотраслевых балансов для исследования торговли и инноваций, теории графов и опросов. Эксперты Европейской комиссии по наблюдению за развитием малых и средних предприятий разработали модель жизненного цикла «идеального» регионального 
(территориального) кластера, подробно описанную в статье «Regional Clusters in Europe» (издание Обсерватории Европейского МСП № 3 за 2002 год за 2002 год).

Научное исследование кластеров в русскоязычной литературе активизировалось только последние несколько лет благодаря работам таких авторов, как Ю.В. Винокурова, которая в своей диссертации «Управление развитием пространственно-интегрированных форм организации промышленности крупного города» рассматривает кластер как организационную форму экономики малого региона, или Г.А. Яшева, работающая над методиками формирования кластерной политики в повышении конкурентоспособности национальной экономики, изучающей конкурентные преимущества кластера в контексте сетевого сотрудничества и государственночастного партнерства.

Многие проблемы остаются не до конца раскрытыми, например последовательность организации кластеров в экономике регионов, институциональное обеспечение кластерного подхода. Основной упор при изучении явления кластеризации экономики делается на сферу производства, в то время как сфера услуг, к которой и относится логистический рынок, остается в стороне.

\section{РЕЗУЛЬТАТЫ И ИХ ОБСУЖДЕНИЕ}

Обратимся к определению понятия «кластер». По мнению М. Портера «кластер - это группа географически соседствующих, взаимосвязанных компаний (поставщики, производители и др.) и связанных с ними организаций (образовательные заведения, органы государственного управления, инфраструктурные компании), действующих в определенных сферах и взаимодополняющих друг друга».[2, 389].

Из этого определения вытекает несколько отличительных особенностей кластеров. Так, все входящие в кластер предприятия территориально локализованы, что дает возможность использовать сконцентрированные на данной территории ресурсы (капитал, рабочую силу, географическое положение). Однако не все предприятия, находящиеся на определенной территории, можно отнести к кластеру, а только те, которые принадлежат к связанным (смежным) отраслям. Постоянное взаимодействие между участниками кластера способствует формальному и неформальному обмену информацией, знаниями, сотрудничеству между предприятиями с взаимодополняющими видами деятельности, функциями, активами и профессиональными навыками. При таких условиях успех одной фирмы будет способствовать развитию другой, за счет эффекта масштаба повышается эффективность деятельности как каждой отдельной фирмы, так и кластера вообще. Все предприятия в кластере находятся в тесных широкоформатных разносторонних связях между собой, то есть, связи выстраиваются не только посредствам контрактов, но и зачастую выходят за рамки деловых отношений. Однако при этом между вышеуказанными предприятиями сохраняется конкуренция, которая является неотъемлемой частью инновационного развития отрасли. Таким образом, кластер представляет собой некую форму организации предприятий (фирм), внутри которой происходит как конкурентная борьба, 
так и сотрудничество. Все указанные отличительные особенности важны в равной мере, и исключить какой-либо пункт, не потеряв при этом в понятии самого кластера, не представляется возможным.

Кластерный подход в развитии экономики Республики Беларусь закреплен на правительственном уровне несколькими нормативно-правовыми документами. Первым в этом ряду и основополагающим стало Постановление Совета Министров Республики Беларусь от 26 мая 2011 г. № 669 «О государственной программе инновационного развития Республики Беларусь на 2011-2015 годы». Целью Программы инновационного

развития является «создание конкурентоспособной, инновационной, высокотехнологичной, ресурсо- и энергосберегающей, экологически безопасной экономики посредствам изменения модели государственного управления промышленностью и перехода к формированию государственной и структурной политики на основе кластерного подхода». [3] В рамках Программы планируется создать химический, промышленный, авто-тракторо-строительный, химико-текстильный и ИТ-кластеры.

По мнению ряда авторов, экономический рост в кластере достигается за счет согласования интересов участников регионального сообщества, установления партнерских отношений между субъектами кластера благодаря активному включению государственных структур в его функционирование, например через механизмы государственно-частного партнерства, создания социально-предпринимательских корпораций на территории кластера. [4] Такой подход отражен и в самой терминологии, используемой в законодательстве Республики Беларусь. Так, в соответствии с Постановлением Совета Министров Республики Беларусь от 18 февраля 2013 г. № 113 «Об утверждении концепции формирования и развития наноиндустрии в Республике Беларусь и плана мероприятий по ее реализации» кластером является «совокупность юридических лиц и индивидуальных предпринимателей, территориально локализованных, взаимодействующих между собой на договорной основе и участвующих в процессе создания добавленной стоимости». [5] Такой же подход использован и в определении промышленного кластера, закрепленного в Постановлении Совета Министров Республики Беларусь от 5 июля 2012 г. № 622 «Об утверждении программы развития промышленного комплекса Республики Беларусь на период до 2020 года»: «промышленный кластер - группа технологически интегрированных промышленных организаций, формирующих единую цепочку создания добавленной стоимости и характеризующихся общностью коммерческих интересов, сосредоточенных на определенной территории, взаимодействие которых усиливает их конкурентные преимущества на отраслевом, национальном и мировом рынках».[6]

В данных определениях в качестве отличительных признаков кластера выделяются территориальная локализация, создание каждым участником добавленной стоимости, взаимодействий участников кластера, при этом делается упор на взаимодействие на договорной основе. Однако при таком подходе исключен один из признаков кластера - конкуренция между участниками. Постановлением Совета Министров №662 формами объединений промышленных 
организаций в хозяйственные общества кластерного типа определены холдинги, совместные предприятия, другие производственные и научно-производственные объединения. Таким образом, белорусский законодатель предполагает, что кластеризация белорусской экономики будет происходить исключительно путем интеграции субъектов хозяйствования. Наибольшую выгоду при таком подходе можно получить в случае наличия эффективной организационной структуры на уровне образования, научных исследований, внедрений разработок в массовое производство.

Наибольшее распространение в нашей стране в качестве хозяйственных обществ кластерного типа получили холдинги. В соответствии с Указом Президента Республики Беларусь от 28 декабря 2009 г. № 660 «О некоторых вопросах создания и деятельности холдингов в Республике Беларусь» холдингом является «объединение юридических лиц, в котором одно из юридических лиц - коммерческая организация - является управляющей компанией холдинга в силу возможности оказывать влияние на решения, принимаемые другими юридическими лицами участниками холдинга (дочерними компаниями холдинга) либо физическое лицо - собственник имущества унитарных предприятий, простых (обыкновенных) акций (долей в уставных фондах) хозяйственных обществ, осуществляет управление (участвует в управлении) этими коммерческими организациями без образования управляющей компании холдинга».[7] Такая форма собственности как холдинг, предполагает зависимость участников холдинга, возможность оказывать влияние на решения дочерних предприятий. Под руководством управляющей компании участники холдинга проводят согласованную финансовую, инвестиционную и производственную политику, разрабатывают планы перспективного развития холдинга. Таким образом, холдинг представляет собой не просто объединение связанных между собой хозяйствующих субъектов в рамках некой отрасли с целью более рационального использования ресурсов или создания общей базы для проведения научно-исследовательских работ, а объединение с единым центром управления, что в зависимости от занимаемой доли рынка будет попадать под контроль антимонопольного законодательства. Кластер же представляет собой гибкую структуру, не предполагающую централизации управления, а базирующуюся на внутренней конкуренции.

Более того, зачастую в белорусском законодательстве термин «кластер» и «холдинг» употребляются как однородные. Например, в Постановлении Совета Министров от 29 декабря 2012 г. № 1242 «О программе государственной поддержки малого и среднего предпринимательства в Республике Беларусь на 2013-2015 годы» говорится о том, что «реализация мероприятий Программы государственной поддержки малого и среднего предпринимательства в Республике Беларусь на 2013 - 2015 годы будет способствовать созданию благоприятных условий ведения бизнеса для субъектов хозяйствования всех форм собственности и дальнейшему развитию добросовестной конкуренции между ними, поощрению предпринимательской инициативы, созданию крупных интегрированных производственных структур (холдингов, кластеров) (...)». [8]

Применение кластерного подхода в развитии белорусской экономики на нормативном уровне закреплено за развитием промышленного сектора экономики (исключение составляет ИТ- 
кластер и научно-технологический парк). Однако не стоит пренебрегать использованием кластерного подхода в развитии сферы услуг. Наиболее перспективной областью в этом направлении ввиду развития Таможенного союза Республики Беларусь, Республики Казахстан и Российской Федерации для нашей страны является логистическая деятельность.

На данном этапе стимулирование логистического рынка в Беларуси происходит в рамках Программы развития в Республике Беларусь логистической системы на период до 2015 г., утвержденной постановлением Совета Министров №1249 от 29 августа 2008 г. Под логистической системой понимается «сложная организационно завершенная (структурированная) экономическая система, которая состоит из элементов-звеньев (транспортно- и оптово-логистических (торговологистических) центров), взаимосвязанных между собой и взаимодействующих посредством информационного обмена в целях достижения эффективного управления цепями поставок товаров и грузов, с участием республиканских и местных органов государственного управления, заинтересованных организаций, располагающих транспортными, складскими, экспедиторскими, информационными, финансовыми, сертификационными, страховыми и производственными структурами».[9] В данном определении делается упор на транспортно-логистические центры, представляющие широкий спектр не только логистических, но и сопутствующих услуг (банковские, страховые, услуги по бытовому обслуживанию), как основной элемент логистической системы. В качестве логистической системы можно рассматривать промышленные предприятия, объединения, комплексы, торговые фирмы, экономические регионы страны, инфраструктуру страны (транспорт) и др.

Транспортно-логистический кластер представляет собой «отраслевой кластер, конечной продукцией которого является транспортно-логистические услуги в грузовом секторе, пассажирском секторе или в обоих». [10] Особенностью кластеров является широкий состав участников - компании-поставщики транспортных, логистических, ремонтных, финансовых, страховых услуг, конкурирующих между собой, но преследующих общую цель эффективного обслуживания экспортных, импортных и транзитных потоков. Система взаимоотношений между участниками логистического кластера весьма сложна по своей природе и включает в себя организационный, экономический, правовой, информационно-коммуникативный, информационный и прочие механизмы. Таким образом, логистический кластер является более широким понятием и в отличие от логистической системы не фокусирует все свое внимание на транспортно-логистических центрах. Состав участников и структура кластера не являются стабильными и определяются набором потребностей субъектов хозяйствования на данном рынке, кластерообразующим предприятием (несколькими предприятиями), являющимся ядром кластера, потенциалом развития, влиянием факторов внешней среды. Кластер, как правило, не является жестко сформированной структурой и должны быть саморазвивающимися, что позволяет выступать логистическому кластеру в качестве платформы для взаимодействия любых хозяйствующих субъектов по вопросам формирования цепи поставок товаров. 
Выделяют 3 вида транспортно-логистических кластеров: портовые, пограничные и региональные. Учитывая геоэкономическое положение Беларуси и сложившиеся товаротранспортные потоки, для нашей страны представляют интерес последние два вида.

В условиях функционирования Таможенного союза и Единого экономического пространства проблема развития логистического кластера в Беларуси становится особенно актуальной. Много говорится об уникальном геоэкономическом положении, о проходящих транспортных коридорах, однако стоит принимать во внимание, что регионы соседних стран, например области г. Москвы и г. Санкт-Петербурга, Омской области совместно с регионами Казахстана намерены развиваться в данном направлении. И имеющиеся условия создания транспортно-логистического кластера в этих регионах принципиально не отличаются от белорусских. В связи с этим для перераспределения транзитных потоков, проходящих по территории стран-участниц ЕЭП, Беларуси следует создать дополнительные конкурентные преимущества.

Поспособствовать развитию белорусского логистического кластера может наличие в стране конкурентоспособных родственных или поддерживающих отраслей. При этом под родственными понимаются такие отрасли, в которых фирмы могут осуществлять взаимодействие между собой в процессе формирование цепочки ценностей, а также отрасли, имеющие дело с взаимодополняющими продуктами, такими как компьютеры или программное обеспечение. В таких случаях взаимодействие между фирмами данных отраслей происходит в сфере развития технологий, производства, распространения маркетинга или сервиса. [11] Для логистического кластера в качестве таких отраслей может выступать, к примеру, производство грузовых транспортных средств, создание программного обеспечения, используемого в логистических центрах (складах).

Наличие спроса на внутреннем рынке также положительно скажется на процессе формирования логистического кластера, так как местный покупатель, как правило, более требовательный и разборчивый, что заставляет фирмы быстрее вводить новации и добиваться конкурентных преимуществ. Кроме того, потребности местных покупателей доходят до субъектов хозяйствования раньше и точнее, чем до международных конкурентов. При наличии достаточно высокого уровня спроса фирма может выиграть, используя эффект масштаба, а также высокий спрос будет привлекать инвестиции. Основными свойствами внутреннего спроса являются те, которые обеспечивают начальный стимул для инвестирования и внедрения новаций, достаточных для успешной конкуренции в растущем со временем количестве развитых сегментов. [12]

Положительное влияние на динамику спроса на внутреннем рынке может оказать и развитие конкурентоспособных на мировом рынке экспортеров, нуждающихся в логистических услугах. Однако в настоящее время все более ли менее крупные экспортеры удовлетворяют потребность в логистических услугах собственными силами, так ими производится примерно 70\% всего объема логистических операций. [13] Все постсоветские страны, и Республика Беларусь не исключение, входят в число стран с высоким уровнем логистических издержек (основные затраты приходятся на управление запасами, складскую и транспортную логистику). Причиной этому является 
сложившееся и ставшее традиционным отношение к логистике как к вспомогательному производству по остаточному принципу. Решением проблемы может стать логистический аутсорсинга, суть которого заключается в отсутствии необходимости использования собственных ресурсов для организации логистических операций и их передаче внешнему партнеру. Таким образом, компания избавляется от неэффективных и непрофильных бизнес-процессов, что позволит ей оптимизировать структуру добавленной стоимости и высвободить капитал для развития основных видов деятельности. Передача логистических услуг на аутсорсинг специализированным сторонним организациям осуществляется в Беларуси редко, и в большинстве случаев организациями с частной формой собственности, а не с государственной. Исходя из того, что в качестве основной институциональной формы развития белорусских кластеров в законодательстве предусмотрены холдинги, то, возможно, более эффективным для предприятий будет использование инсорсинга, в таком случае в качестве исполнителя выступает дочернее или аффилированное юридическое лицо.

Немаловажное значение для успешного функционирования логистического кластера имеет выбранная стратегия управления и структура фирмы. Ни одна из систем управления не может подходить абсолютно всем компаниям. Для фирмы, осуществляющей свою деятельность в области транспортной логистики, наилучшим будет выбор более гибких и демократических структур, способных реагировать на быстрые изменения рынка. Многое в этой сфере зависит от непосредственной деятельности отдельного работника, поэтому особую роль играет система вознаграждения на предприятии, сложившийся микроклимат, отношение к власти. Например, на территории Республики Беларусь одним из крупнейших предприятий на рынке логистических услуг является Республиканское унитарное предприятие «Белтаможсервис», подчиняющееся Государственному таможенному комитету. Подотчетность государственному органу, жесткая управленческая структура, недостаточная гибкость не способствуют повышению конкурентоспособности данного предприятия.

В своих исследованиях М.Портер установил взаимосвязь между сильным соперничеством на внутреннем рынке и созданием и поддержанием высокой конкурентоспособности в отрасли. В стране, достигшей ведущих мировых позиций в определенной отрасли, часто имеется ряд сильных местных конкурентов. Конкуренция принуждает фирму совершенствовать производственные процессы и внедрять новшества. Наличие местных конкурентов сводит на нет те преимущества, которые имеются уже потому, что данная фирма действует на своем родном рынке. При этом процесс конкуренции на внутреннем рынке создает преимущество для национальной отрасли в целом, а не только для отдельных фирм. Конкурентное соперничество в одной географической местности одновременно отражает и увеличивает эти преимущества. [14] Исходя из такой позиции, реализация процесса кластеризации экономики в форме создания холдингов, как предусмотрено законодательством Республики Беларусь, представляется не вполне целесообразным. Для организационного обеспечения кластеров в мировой практике наибольшее распространение получила промышленная ассоциация. Ассоциация представляет собой 
некоммерческую организацию. Члены ассоциации, уплачивая вступительные и членские взносы, получают услуги ассоциации в области развития образования, активизации инноваций, совершенствования маркетинга и т. д. бесплатно или по льготным тарифам, при этом остается возможная конкуренция между участниками.

Политика правительства может как положительно, так и отрицательно влиять на формирование конкурентоспособной отрасли. Например, государственные закупки стимулируют родственные и поддерживающие отрасли, а антимонопольное законодательство влияет на внутреннюю конкуренцию. Однако, ограничив конкуренцию на внутреннем рынке с целью стимулирования развития, облегчения бремени и сохранения имеющихся, зачастую убыточных, предприятий, госорганы убирают стимул для самостоятельного развития и внедрения новаций.

Все указанные выше факторы находятся во взаимозависимости и влияют друг на друга, создавая особую синергетическую систему. Успех компаний кластера, основанный только лишь на одном-двух факторах, будет недолгим. Одновременно с развитием и рациональным использованием факторных условий (ресурсы, навыки, квалифицированная рабочая сила, геоэкономическое положение), чтобы получить и удержать конкурентное преимущество в логистической сфере, необходимо иметь и развивать преимущество во всех остальных перечисленных факторах.

\section{ВЫВОдЫ}

В условиях функционирования Таможенного союза и Единого экономического пространства проблема развития логистического рынка в Беларуси становится особенно актуальной. В виду специфики данного рынка, а также выбора Правительством Республики Беларусь формы развития основных направлений национальной экономики в виде кластеров, наиболее перспективной организационной формой развивающегося логистического рынка также представляется кластер.

На данный момент существуют некоторые противоречия общей теории кластеров и норм, закрепленных белорусским законодательством, в частности определение холдинга в качестве основного вида хозяйственных обществ кластерного типа. Кроме того, в соответствии с принятой Программой развития в Республике Беларусь логистической системы на период до 2015 г. развитие логистического рынка нашей страны осуществляется в форме логистической системы. В отличие от логистической системы логистический кластер - более широкое понятие. Кластер, как правило, не является жестко сформированной структурой, должен быть саморазвивающимся и выступать в качестве платформы для взаимодействия множества хозяйствующих субъектов по вопросам формирования цепи поставок товаров.

Создание белорусского логистического кластера позволит усовершенствовать процесс управления логистическими услугами, повысит конкурентоспособность региональной и государственной экономики и создаст условия для интеграции в международное пространство. Однако для привлечения транзитных потоков помимо рационального использования имеющихся ресурсов, таких как природно-географические положение и экономические условия региона, 
наличие кадрового потенциала, необходимо создать дополнительные конкурентные преимущества, которые позволили бы сформировать более привлекательный рынок логистических услуг в сравнении с рынком наших соседей.

\section{ЛИТЕРАТУРА}

1. Государства-члены Таможенного союза и Единого экономического пространства. 2005-2012.: краткий статистический сборник // Евразийская экономическая комиссия. - М: Типография Главного межрегионального центра обработки и распространения статистической информации Федеральной службы государственной статистики (ГМЦ Росстата), 2013.— 128 с. C. 62 .

2. Портер, М. Е. Конкуренция / М.Е. Портер - М.: Вильямс, 2010 - 592 с. - С. 389.

3. О государственной программе инновационного развития Республики Беларусь на 2011-2015 год: Постановление Совета Министров Республики Беларусь от 26 мая 2011 г. № 669 // Консультант Плюс: Беларусь. Технология 3000 [Электронный ресурс] / ООО «ЮрСпектр», Нац. центр правовой информ.Респ. Беларусь. - Минск, 2013.

4. Яшева, Г.А. Обоснование кластерного подхода к повышению эффективности регионального производства / Г.А. Яшева // Вестник «Витебский государственный технологический университет». - 2012. - № 23, С. 171-181.

5. Об утверждении концепции формирования и развития наноиндустрии в Республике Беларусь и плана мероприятий по ее реализации: Постановление Совета Министров Республики Беларусь от 18 февраля 2013 г. № 113 // Консультант Плюс: Беларусь. Технология 3000 [Электронный ресурс] / ООО «ЮрСпектр», Нац. центр правовой информ.Респ. Беларусь. - Минск, 2013.

6. Об утверждении программы развития промышленного комплекса Республики Беларусь на период до 2020 года: Постановление Совета Министров Республики Беларусь от 5 июля 2012 г. № 622 // Консультант Плюс: Беларусь. Технология 3000 [Электронный ресурс] / ООО «ЮрСпектр», Нац. центр правовой информ. Респ. Беларусь. - Минск, 2013.

7. О некоторых вопросах создания и деятельности холдингов в Республике Беларусь: Указ Президента Республики Беларусь от 28 декабря 2009 г. № 660 // Консультант Плюс: Беларусь. Технология 3000 [Электронный ресурс] / ООО «ЮрСпектр», Нац. центр правовой информ. Респ. Беларусь. - Минск, 2013.

8. $\quad$ О программе государственной поддержки малого и среднего предпринимательства в Республике Беларусь на 2013-2015 годы: Постановление Совета Министров от 29 декабря 2012 г. № 1242 // Консультант Плюс: Беларусь. Технология 3000 [Электронный ресурс] / ООО «ЮрСпектр», Нац. центр правовой информ.Респ. Беларусь. - Минск, 2013.

9. $\quad$ О программе развития логистической системы Республики Беларусь на период до 2015 года: Постановление Совета Министров Респ. Беларусь от 29 авг. 2008 г. № 1249 // 
Консультант Плюс: Беларусь. Технология 3000 [Электронный ресурс] / ООО «ЮрСпектр», Нац. центр правовой информ. Респ. Беларусь. - Минск, 2013.

10. Транспортно-логистический кластер в Европейском союзе // Селективный обзор. Самара, 2011. $-23 \mathrm{c}$.

11. Портер, М.Е./Международная конкуренция = The Competitive Advantage of Nations/ М.Е. Портер. Пер. С англ. И.В. Кавсюка и др. - М.: Международные отношения, 1993. - 896 с. - С. 126.

12. Портер, М.Е./Международная конкуренция = The Competitive Advantage of Nations/ М.Е. Портер. Пер. С англ. И.В. Кавсюка и др. - М.: Международные отношения, 1993. - 896 с. - С. 121-122.

13. Транспортные перспективы Республики Беларусь в рамках ЕЭС // Компас экспедитора и перевозчика. - 2013 - №1. - С. 18-22.

14. Портер, М.Е./Международная конкуренция = The Competitive Advantage of Nations/ М.Е. Портер. Пер. С англ. И.В. Кавсюка и др. - М.: Международные отношения, 1993. - 896 с. - С. 139-141. 